\title{
Managing elevated intraocular pressure in a patient with optic nerve hypoplasia
}

This article was published in the following Dove Press journal:

Clinical Optometry

19 October 2009

Number of times this article has been viewed

\section{Karina Marcovitch Joseph Sowka}

Nova Southeastern University College of Optometry, Davie, FL, USA
Correspondence: Karina Marcovitch Nova Southeastern University College of Optometry, 3200 South University Drive, Ft. Lauderdale, FL 33322, USA Email karina.marcovitch@gmail.com
Background: Optic nerve hypoplasia $(\mathrm{ONH})$ is a congenital optic disc anomaly, often manifesting with visual deficits.

Case: A 51-year-old woman with a history of bilateral amblyopia was referred for glaucoma evaluation due to elevated intraocular pressure. The patient demonstrated the classic nerve head appearance of bilateral ONH with "double ring sign" and indistinguishable cupping. Despite demonstrating functional and structural measurements consistent with glaucomatous optic neuropathy, it was felt that these deficits were more likely longstanding and secondary to $\mathrm{ONH}$. Additionally, in the absence of any amblyogenic factors, it was also concluded that the patient's bilateral "amblyopia" was the result of ONH. In that the patient presented with a significant and modifiable risk factor for glaucomatous development and pre-existing retinal nerve fiber layer and visual field defects, the patient was treated with topical glaucoma medications.

Conclusion: Diagnosing glaucoma in patients with concurrent anomalies is a clinical conundrum. This report provides a review of $\mathrm{ONH}$ with emphasis on the common misdiagnosis of amblyopia in these patients as well as presenting a strategy for diagnosing and managing glaucoma in patients with preexisting, confounding conditions.

Keywords: optic nerve hypoplasia, glaucoma, visual field loss, scanning laser polarimetry, threshold automated perimetry

\section{Introduction}

Optic nerve hypoplasia $(\mathrm{ONH})$ is a nonprogressive congenital anomaly of the optic nerve presenting with mild to severe vision loss and may be associated with central nervous system (CNS) anomalies. ONH occurs unilaterally or bilaterally and is thought to be the consequence of ganglion cell mal-development resulting in fewer nerve fibers exiting the eye via the scleral canal. ${ }^{1}$ Ophthalmoscopically, this anomaly may be identified based upon an appearance described as the "double ring sign" where a small optic disc is surrounded by a pale halo of sclera bordered on either side with a rim of pigment. ${ }^{1-4}$ A diminished nerve fiber layer light reflex may also be appreciated. ${ }^{5-7}$

\section{Case report}

A 51-year-old Caucasian female was referred for glaucoma evaluation due to elevated intraocular pressures in both eyes during her yearly comprehensive eye exam two weeks earlier. Her ocular history was significant for bilateral amblyopia, worse in the left eye, which had not improved with therapy, per her report. The patient denied injury or surgery to the eyes, but did admit a history of domestic abuse several years ago which did not involve either eye. Medical history was significant for type 2 diabetes mellitus, 
diagnosed eight years earlier, osteoarthritis, degenerative joint disease, and elevated triglycerides.

Entering visual acuity with correction on pinhole was 20/30 OD and 20/40 OS. The patient had not yet filled her recent spectacle prescription, but previous records indicated a refractive error of low myopic astigmatism OU and presbyopia. Pupils were equal, round and reactive to light without afferent pupillary defects and color vision was normal in each eye. Extraocular motilities were smooth, accurate, full and extensive in both eyes. An intermittent left exotropia was elicited on cover testing, however, no strabismus was observed throughout the remainder of the examination. Anterior segment biomicroscopy was significant for $1+$ nuclear sclerotic cataract in both eyes. Goldman applanation tonometry measured intraocular pressures of $28 \mathrm{~mm} \mathrm{Hg}$ OD and $26 \mathrm{~mm} \mathrm{Hg}$ OS. Pachymetry revealed central corneal thickness of 560 microns OD and 548 microns OS. Anterior chamber angles were open on gonioscopy to at least scleral spur 360 degrees in both eyes. There were no angle anomalies present in either eye. Dilated fundus examination revealed bilateral optic nerves appearing pink and small centrally with distinct margins and prominent surrounding white scleral crescents in both eyes (Figure 1). Cupping was indistinguishable in each eye. The retinal vessels were of normal caliber and orientation. There were few small pinpoint drusen around the macula of the right eye. The left macula was flat and even and there was no evidence of macular edema in either eye. The peripheral retinal exam was unremarkable OU and there was no evidence of diabetic retinopathy.

Additional glaucoma testing was initiated and included scanning laser polarimetry nerve fiber layer analysis (Figure 2). The image quality was good and showed small nerves with abnormal nerve fiber layer with multiple, significant departures from the normative database in each eye. Threshold automated perimetry with a Humphrey 24-2 SITA Standard strategy was performed (Figure 3) revealing

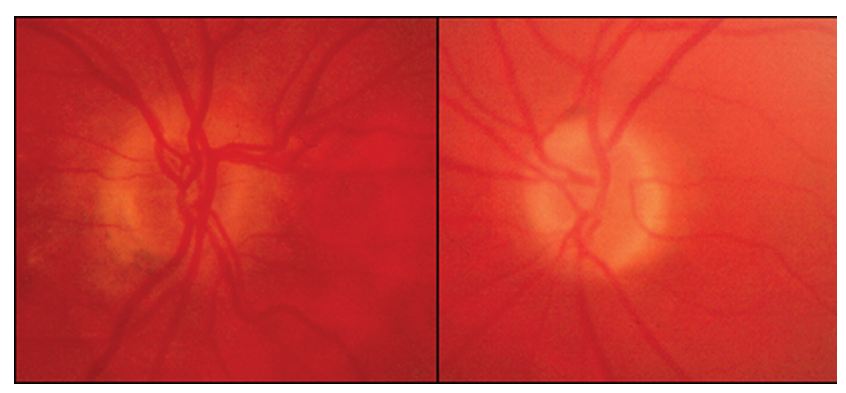

Figure I Right and left optic nerve heads demonstrating the double ring sign in optic nerve head hypoplasia. superior arcuate scotomas in both eyes; the left eye exhibiting a larger defect than the right.

Despite functional and structural measurements consistent with glaucoma, it was felt that these deficits were likely due to ONH. Additionally, in the absence of any amblyogenic factors, it was also concluded that the patient's bilateral "amblyopia" was the result of ONH. In that the patient presented with elevated intraocular pressure, a significant and modifiable risk factor for glaucomatous development, and pre-existing retinal nerve fiber layer and visual field defects, a trial of Travatan $\mathrm{Z}$ was initiated in the left eye.

On two-week follow-up the patients intraocular pressure was $28 \mathrm{~mm} \mathrm{Hg}$ OD and $19 \mathrm{~mm} \mathrm{Hg}$ OS. The patient was then instructed to use the Travatan $\mathrm{Z}$ in both eyes QHS and to return for follow-up in one month. Intraocular pressures after one month were $15 \mathrm{~mm} \mathrm{Hg} \mathrm{OU}$.

\section{Discussion}

ONH was first described in the late 1800's and was considered a rare and isolated disorder. ${ }^{8,9}$ It is now recognized as one of the most common congenital ocular anomalies. The degree of hypoplasia and its clinical signs vary tremendously and may occur in isolation or may be associated with CNS issues. Bilateral forms may present with nystagmus, whereas unilateral forms have been associated with strabismus and afferent pupillary defect. There is no sex or race predilection ${ }^{6}$. Several predisposing factors have been described including low maternal age, being the first born, maternal gestational diabetes etc. In particular, $\mathrm{ONH}$ has been associated with septo-optic-pituitary dysplasia syndrome. ${ }^{6}$

In the most obvious cases, the hypoplastic nerve will demonstrate the double ring sign. However, the disc may have subtle structural changes, which makes the diagnosis of ONH more difficult. The observed size of an optic disc image is dependent on instrumentation magnification and the magnification properties of the eye. Myopic refractive errors can make the hypoplastic disc appear normal in size, whereas the hyperopic eye may make an average disc appear small. Several methods are used to measure the true size of the optic disc including histomorphometry, planimetry, confocal scanning laser ophthalmoscopy and optical coherence tomography. Clinically, it is not necessary to measure the exact size of the nerve but rather to estimate its size and ascertain whether the disc is small $(<1.5 \mathrm{~mm})$ average or large $(>2.2 \mathrm{~mm})$, In biomicroscopy, the average disc area and vertical area of the disc can be estimated with the use of high powered convex lenses, such as $+90 \mathrm{D},+78 \mathrm{D}$, +60 D. Fundus structures are measured using the slit beam 

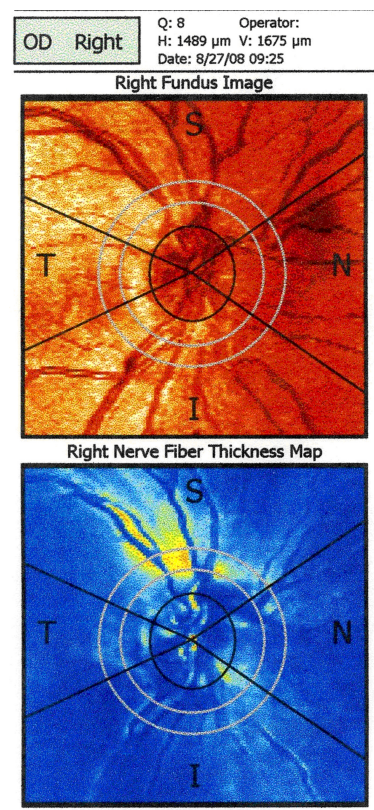

Right Deviation Map (from Normal)
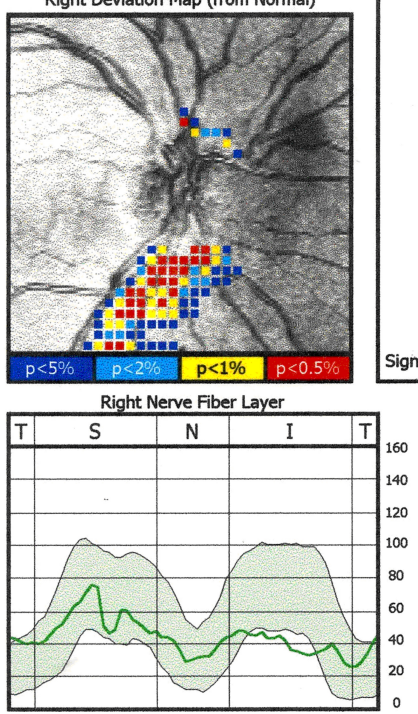

\begin{tabular}{|c|c|c|}
\hline $\begin{array}{c}\text { TSNIT } \\
\text { Parameters }\end{array}$ & $\begin{array}{c}\text { OD } \\
\text { Actual Val. }\end{array}$ & $\begin{array}{c}\text { OS } \\
\text { Actual Val. }\end{array}$ \\
\hline TSNIT Average & 44.6 & 38.0 \\
\hline Superior Average & 56.0 & 51.8 \\
\hline Inferior Average & 39.5 & 30.9 \\
\hline TSNIT Std. Dev. & 10.9 & 11.5 \\
\hline Inter-Eye Symmetry & \multicolumn{2}{|c|}{0.81} \\
\hline NFI & 43 & 54 \\
\hline
\end{tabular}

Thickness Map Legend (microns)

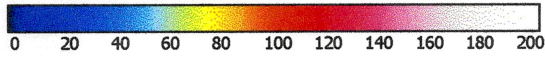

Impression / Plan:
.
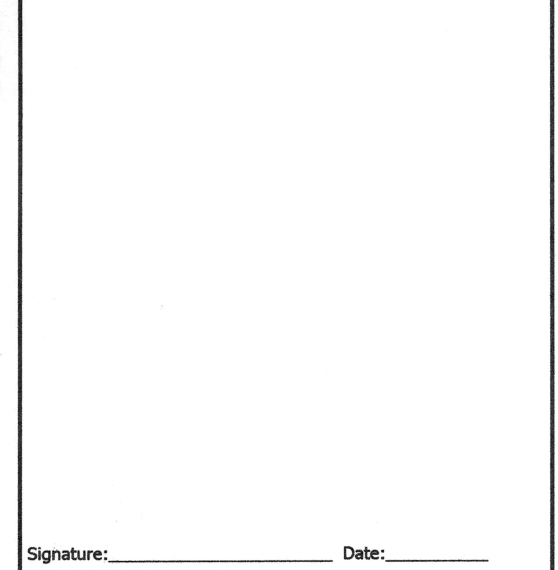
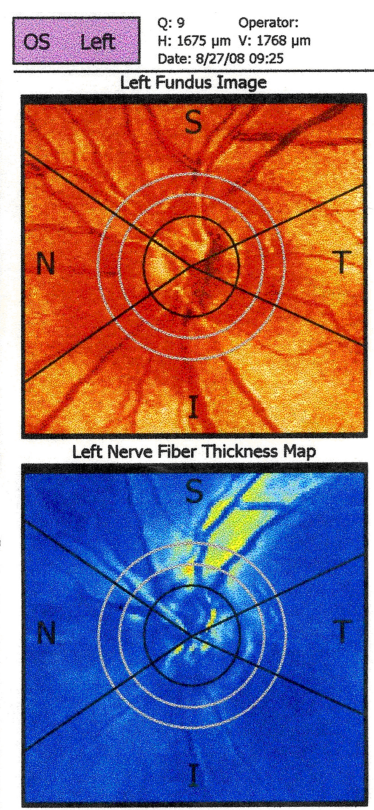

Left Deviation Map (from Normal)

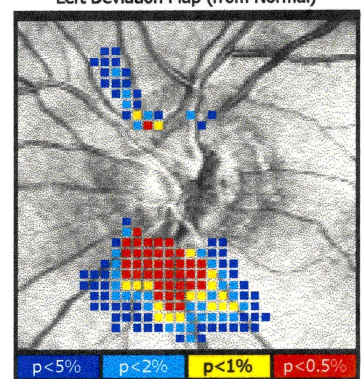

Left Nerve Fiber Layer
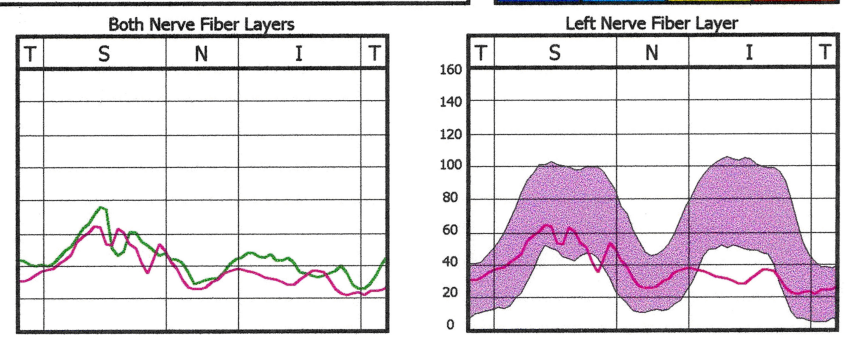

Figure 2 Scanning laser polarimetry.

light and are multiplied by a conversion factor for each lens (Table 1). ${ }^{10}$ However, the conversion factors are limited in that they are vertex distance specific. Another easy method of estimating the optic disc size is by comparing its diameter to that of the central retinal vein. The veins exiting the optic nerve in $\mathrm{ONH}$ are generally normal in terms of size and caliber, but may appear large compared to the size of the optic nerve. The horizontal diameter of the average optic nerve head is approximately $0.90-2.6 \mathrm{~mm}^{11}$ and the diameter of a central retinal vein entering the optic nerve is approximately $0.125 \mathrm{~mm}$. Therefore, one would expect that at least eight retinal veins side-by-side could cover the diameter of the average optic nerve head. Fundus photography may be used to identify abnormally small or large nerves by determining the disc-macula distance to disc diameter ratio (DM/DD), whereby the distance from the center of the optic disc to the macula is divided by the diameter of the optic disc. A ratio of 3 or more has been shown to be supportive evidence of ONH. ${ }^{12-15}$ However, the ratio may be falsely high in high myopes. ${ }^{16}$ Several other techniques have been used to diagnose the condition, including magnetic resonance imaging (MRI) and nerve fiber layer analysis. ${ }^{8,9}$

In mild cases of $\mathrm{ONH}$, visual acuity may be normal or only mildly reduced and is therefore occasionally misdiagnosed as amblyopia. In a study by Acers patients with $\mathrm{ONH}$ demonstrated vision that ranged from normal to light 


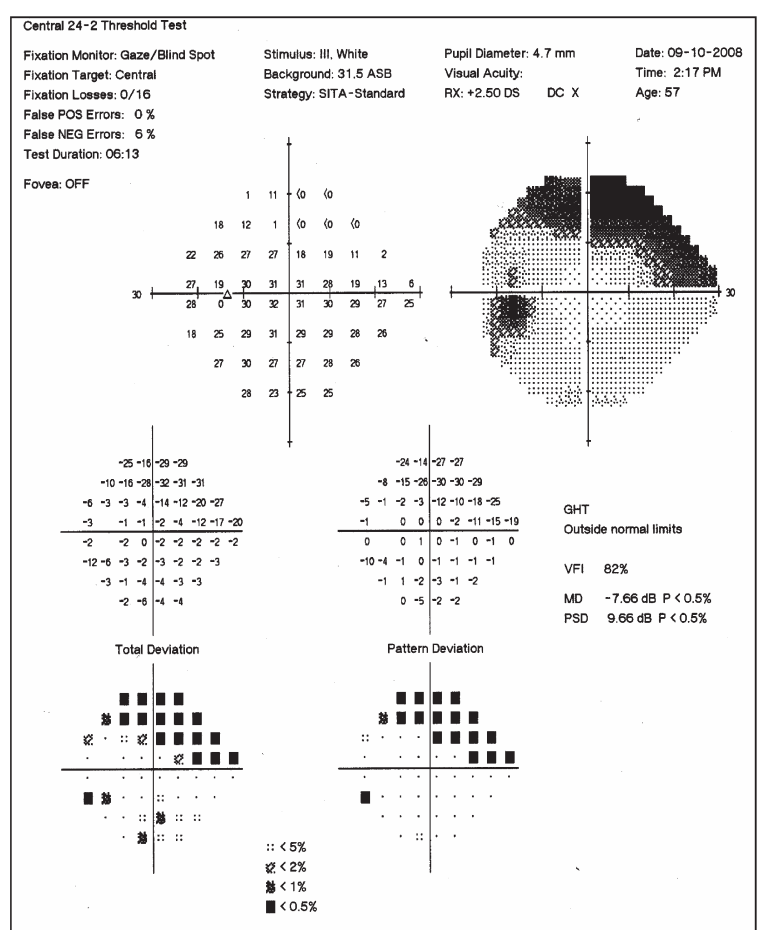

Figure 3 Humphrey visual fields, SITA-standard central 24-2 threshold.

perception with little correlation between the size of the optic nerve and the visual function. ${ }^{8}$ This is because visual acuity is based on the integrity of the papillomoacular fibers. Patients may demonstrate visual field defects that remain stable over time, unless concomitant disease exists ${ }^{8}$. These defects include, but are not limited to, bitemporal, arcuate, central or nasal scotomas and generalized constriction of the visual field.

ONH visual field defects may mimic that caused by processes that cause progressive degeneration, such as glaucoma. In that the patient presented here demonstrated bilateral superior arcuate scotomas, retinal nerve fiber layer loss, and elevated intraocular pressure, there existed a clinical conundrum: determining whether the findings were secondary to progressive nerve fiber layer damage from glaucoma, or longstanding and due to $\mathrm{ONH}$, or a combination of both. In this situation, the only way to determine etiology would be to allow for progression by leaving the

Table I Correction factors for funduscopy with high powered convex lenses ${ }^{10}$

\begin{tabular}{llll}
\hline Lens (Volk) & +60 D & +78 D & +90 D \\
\hline Correction factor & $\times 1.0$ & $\times 1.1$ & $\times 1.3$ \\
\hline
\end{tabular}

Abbreviation: D, diopter.

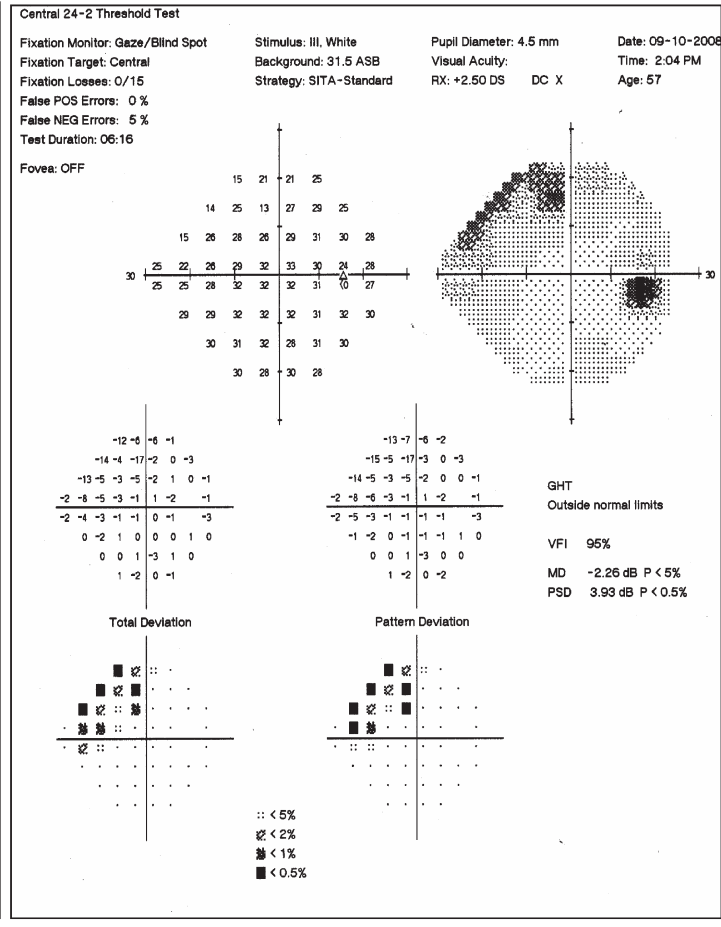

patient untreated, which would be inappropriate. However, as the patient presented with elevated intraocular pressure, a modifiable risk factor for glaucoma, which in addition to the functional and structural loss, prompted treatment with intraocular pressure lowering medication. In the absence of a risk factor for glaucoma development, there is no evidence that lowering statistically normal intraocular pressure benefits patients with $\mathrm{ONH}$.

\section{Conclusion}

The diagnosis of $\mathrm{ONH}$ is often uncertain in the presence of subtle structural and visual changes. An understanding of the structural and functional signs of ONH is essential for proper diagnosis and patient education. Any person with longstanding vision impairment not attributable to an amblyogenic factor, concomitant disease or structural damage, especially those who have had unsuccessful ambylopia treatment, should be suspected for congenital abnormalities such as ONH. Patients with confounding clinical signs present an additional challenge to the clinician, but in the presence of factors modifiable for progressive disease, steps should be taken to manage potential progressive structural damage and vision loss.

\section{Disclosures}

The authors report no conflicts of interest in this work. 


\section{References}

1. Scheie HC, Adler FH. Aplasia of the optic nerve. Arch Ophthalmol. 1941;26:61-70.

2. Hotchkiss ML, Green WR. Optic nerve aplasia and hypoplasia. JPediatr Ophthalmol Strabismus. 1979;16:225-240.

3. Lambert SR, Hoyt CS, Narahara MH. Optic nerve hypoplasia. Surv Ophthalmol. 1987;32:1-9.

4. Zeki SM, Dutton GN. Optic nerve hypoplasia in children. $\mathrm{Br} J$ Ophthalmol. 1990;74:300-304.

5. Fresen L, Holmegaard L. Spectrum of optic nerve hypoplasia. Br J Ophthalmol. 1978;62:7-15.

6. Hellstrom A, Wiklund LM, Svenson E. The clinical and morphologic spectrum of optic nerve hypoplasia. J AAPOS. 1999;3(4):212-220.

7. Kim MR, Park SE, Oh SY. Clinical feature analysis of congenital optic nerve abnormalities. Jpn J Ophthalmol. 2006;50:3:250-255.

8. Acers TE. Optic nerve hypoplasia: septoopticpituitary dysplasia syndrome. Trans Am Ophthalmol Soc. 1981;79:425-457.

9. Hellstrom A, Wiklund LM, Svenson E. Diagnostic value of magnetic resonance imaging and planimetric measurement of optic disc size in confirming optic nerve hypoplasia. J AAPOS. 1999;3:2:104-108.
10. Ansari-Shahrezaei S, Maar NH, Biowski R, Stur M. Biomicroscopic measurement of the optic disc with a high-power positive lens. Invest Ophthalmol Vis Sci. 2001;42:153-157.

11. Jonas JB, Gusek GC, Naumann GOH. Optic disc, cup and neuroretinal rim size, configuration and correlations in normal eyes. Invest Ophthalmol Vis Sci. 1988;29:1151-1158.

12. Awan KJ. Ganglionic neuroretinal aplasia and hypoplasia: aplasia and hypoplasia of optic nerve. Ann Ophthalmol. 1976;8:1193-1202.

13. Wakakura M, Alvarez E. A simple clinical method of assessing patients with optic nerve hypoplasia. The disc-macula distance to disc diameter ratio. Acta Ophthalmol (Kbh). 1987;65:612-617.

14. Alvarez E, Wakakura M, Khan Z, Dutton GN. The disc macula distance to disc diameter ratio: a new test for confirming optic nerve hypoplasia in young children. J Pediatr Ophthalmol Strabismus. 1988;25: $151-154$.

15. Zeki SM, Dudgeon J, Dutton GM. Reappraisal of the ratio of disc to macula/disc diameter in optic nerve hypoplasia. Br J Ophthalmol. 1991;75:538-541.

16. Barr DB, Weir CR, Purdie AT. An appraisal of the disc-macula distance to disc diameter ratio in the assessment of optic disc size. Ophthalmic Physiol Opt. 1999;19:5:265-275.
Clinical Optometry

\section{Publish your work in this journal}

Clinical Optometry is an international, peer-reviewed, open access journal publishing original research, basic science, clinical and epidemiological studies, reviews and evaluations on clinical optometry. All aspects of patient care are addressed within the journal as well as the practice of optometry including economic and business analyses. Basic and clinical

Submit your manuscript here: http://www.dovepress.com/clinical-optometry-journal

\section{Dovepress}

research papers are published that cover all aspects of optics, refraction and its application to the theory and practice of optometry. The manuscript management system is completely online and includes a very quick and fair peer-review system, which is all easy to use. Visit http://www.dovepress. com/testimonials.php to read real quotes from published authors. 